\title{
LAJE MISTA DE BAMBU-CONCRETO LEVE: ESTUDO TEÓRICO E EXPERIMENTAL
}

\section{FLATSLAB WITH CONCRETEAND LIGHTWEIGT CONCRETE:THEORETICALAND EXPERIMENTATE APPROACH}

\section{Caio Cesar Veloso Acosta, M.Sc. (UEL); Gilberto Carbonari, Dr. (UEL)}

\author{
Palavras Chave \\ Bambu; Laje Mista; Desenvolvimento Sustentável; Construção em Bambu
}

\section{Key Words}

Bamboo; Concrete Slab; Bamboo Buildings; Sustainable Develpment

\section{RESUMO}

A busca de novas alternativas para a sustentabilidade na construção civil vem sendo foco de estudos nos últimos anos, visando amenizar os impactos causados pelas ações antrópicas no meio. O bambu é um material com excelentes propriedades mecânicas, de rápida produção para fins estruturais (a partir de 3 anos), baixo custo de produção, leve, de origem natural e totalmente renovável. Este trabalho tem como objetivo verificar a possibilidade da utilização do bambu em lajes de edificações, na forma mista com concreto leve. Para isto, foram desenvolvidas e ensaiadas duas lajes, onde a parte inferior é de bambu da espécie DendrocalamusGiganteus, e a parte superior uma capa de concreto leve com argila expandida. Em uma das lajes todas as varas são cortadas no meio da seção, e na outra, foi mantida a seção natural na região dos nós, na tentativa de melhorar a interface de aderência. Apesar de terem sido ensaiadas somente duas lajes, é possível constatar o ganho significativo de resistência da laje com seção completa na região dos nós.

\section{ABSTRACT}

The search for new alternatives for sustainability in civil construction has been the focus of studies lately, trying to slow down the impacts caused by anthropic actions in the environment. The Bamboo is a material with excellent mechanical characteristics with quickly grown for structural use (tree years), lower production cost, lightweight, natural and renewable. This paper aims to evaluate the use of bamboo in buildings floors as flat slab with permanent shutter. For this, two slabs were developed and test, on the bottom were place the bamboo shutters of DendrocalamusGiganteus species and at the top a lightweight concrete with expanded clay. One of the flat slabs all bamboo rods has been saw at the middle, and in the other, the section of the nodes was maintained, trying to increase the interface strength. Although only two slabs were evaluate, it is possible to verify the singnificative strength increase by using the flat slab with complete nodes. 


\section{INTRODUÇÃO}

A sustentabilidade vem sendo muito debatida nos últimos tempos. Como a construção civil é uma das maiores geradoras de resíduos, temos que buscar novos materiais e novas técnicas que melhorem a eficiência das construções e diminuição dos impactos ambientais causados. Isso pode ser viabilizado reduzindo o consumo dos materiais tradicionais, substituindo por materiais de fontes renováveis, e com menor consumo energético na sua cadeia produtiva. Neste cenário, o bambu surge com uma alternativa viável, pois se trata de um material renovável que utiliza apenas energia solar para sua produção.

O Brasil tem um grande potencial de cultivo de bambus, pois os mesmos se adaptam com facilidade no clima e o solo. Por ser uma espécie de rápido crescimento e grande abundância, o bambu também se apresenta como um material de baixo custo (Oliveira, 2006).

O objetivo principal deste trabalho é o de verificar a possibilidade da utilização do bambu em lajes mistas com concreto leve nas edificações. As lajes têm como finalidade conduzir as cargas de utilização para as vigas e pilares da edificação, garantindo segurança e conforto ao usuário. De acordo Ghavami (2004), um dos fatores mais importantes para a resistência última deste tipo de laje é o cisalhamento na interface bambu-concreto. Sendo assim, neste estudo foram ensaiadas em laboratório duas lajes: em uma laje todas as varas de bambu foram seccionadas no meio (Figura 1), e na outra laje manteve-se a seção natural das varas nas regiões dos nós (Figura 2), com a finalidade de verificar a sua eficiência ao cisalhamento. No estudo foi utilizado bambu da espécie DendrocalamusGiganteus.

Além do estudo experimental, neste trabalho também foram realizadas simulações teóricas do comportamento, com o objetivo de contrastar com os resultados obtidos dos ensaios.

\section{MATERIAIS E MÉTODOS}

\subsection{Coleta do Bambu}

As varas foram coletadas no bambuzal localizado no interior do campus da Universidade Estadual de Londrina (Figura 3), escolhidas de acordo com suas idades e diâmetros, de forma a garantir uma homogeneidade na coleta.

\subsection{Execução das lajes mistas}

Em função das limitações dos equipamentos do laboratório, definiu-se que as duas lajes teriam $3 \mathrm{~m}$ de comprimento, e uma largura próxima de $70 \mathrm{~cm}$. Como o diâmetro externo médio das varas utilizadas para ambas as lajes foi de 13 $\mathrm{cm}$, decidiu-se utilizar 5 varas, resultando em uma largura de $65 \mathrm{~cm}$. A partir da meia cana dos bambus cortados ao meio (6,5 cm de raio externo), foi utilizada uma capa de concreto leve de $6,5 \mathrm{~cm}$, totalizando uma espessura total da laje de 13 $\mathrm{cm}$, coincidindo com diâmetro externo médio dos bambus.

Figura 1 - Laje sem nós.

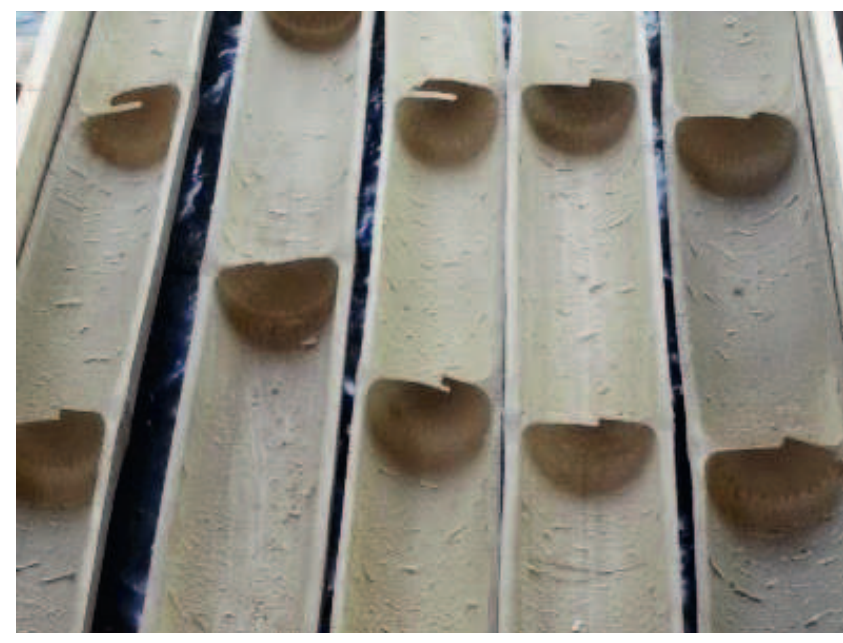

Fonte: Autores

Figura 2 - Laje com nós.

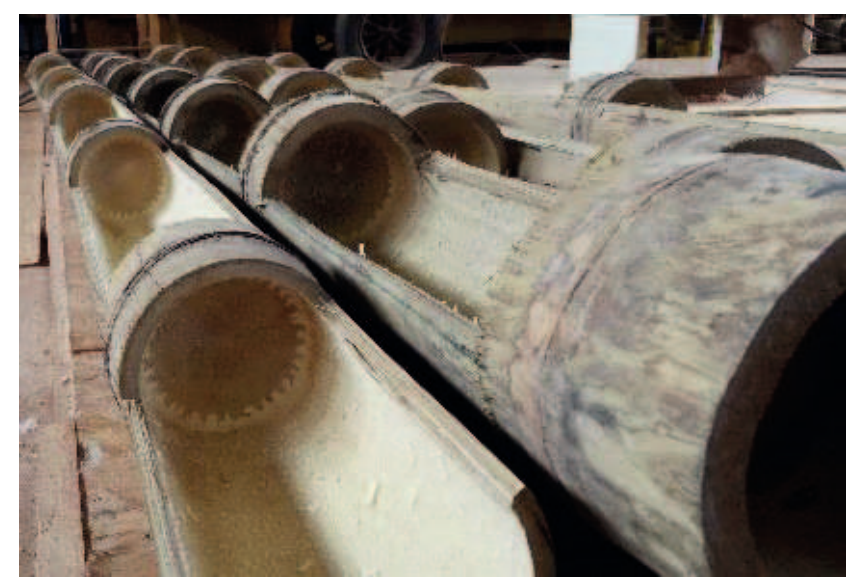

Fonte: Autores

Figura 3 - Bambuzal da UEL.

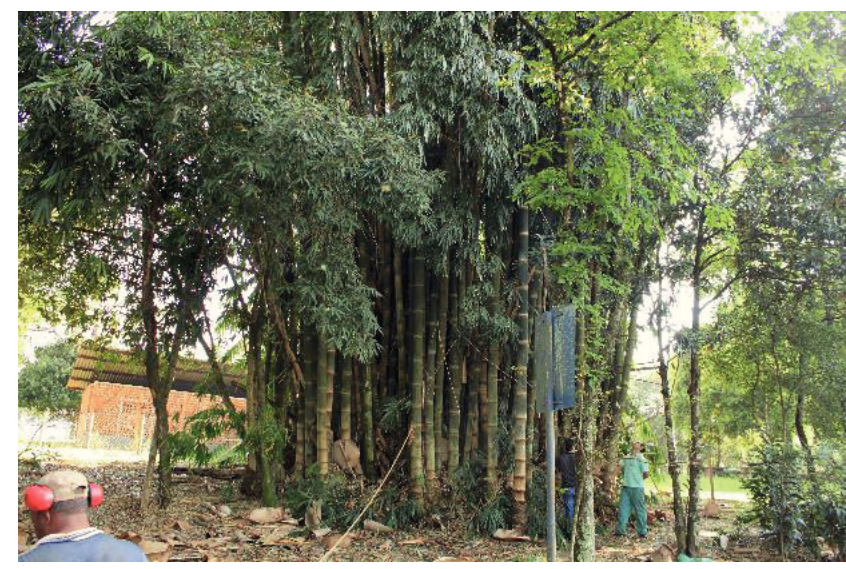

Fonte: Autores 


\subsubsection{Lajes com varas de bambu a meia cana}

Para montagem da laje foram escolhidas três varas com diâmetros e espessuras próximas. As varas foram cortadas ao meio na seção transversal com comprimento de três metros, obtendo-se assim seis peças de bambu "meia-cana".

As seis peças foram dispostas de forma arbitrária, tentando minimizar possíveis folgas entre as varas no sentido longitudinal (Figura 4 e Figura 6). Após a distribuição das varas cortadas na fôrma, foi adicionada uma malha de $30 \times 30 \mathrm{~cm}$ com taliscas de bambu, com a finalidade de melhorar a distribuição das tensões, e homogeneizar a laje como um todo (Figura 5).

Como pode ser observado na Figura 6, devido à falta de retilineidade natural do bambu, algumas folgas entre as varas longitudinais chegaram a aproximadamente $4 \mathrm{~cm}$. Para evitar a perda da pasta de concreto durante a concretagem, e a movimentação das peças na forma, os elementos de bambu foram grampeados, com a colocação de uma fita de papel crepado nas junções das peças.

\subsubsection{Laje com varas de bambu a meia cana en- tre nós e seção plena nos nós}

Foi mantida a seção transversal natural das varas de bambu da laje numa de extensão de $\sim 10 \mathrm{~cm}$ na região dos nós (Figura 7). Para isso, após a marcação da posição dos cortes, foi utilizada uma serra circular para efetuar os cortes da seção das varas, de forma a ter as meias canas na região entre nós. Após os cortes com a serra na direção ortogonal às varas, foram utilizados martelo e formão para romper na direção longitudinal à região a ser destacada da peça.

Neste caso, devido à presença da seção completa das varas junto aos nós, não foi possível utilizar a mesma maIha da laje anterior, pois as taliscas longitudinais ficariam impedidas de serem colocadas. Assim sendo, foram disposta taliscas somente na direção da largura da laje ( $L=65$ $\mathrm{cm})$, a cada $30 \mathrm{~cm}$, aproximadamente.

Da mesma maneira que a laje anterior, as varas de bambu foram grampeadas entre si para evitar movimentação das peças na fôrma, e com fita de papel crepado para evitar a perda de pasta de concreto.

Figura 6 - Espaçamento entre peças.

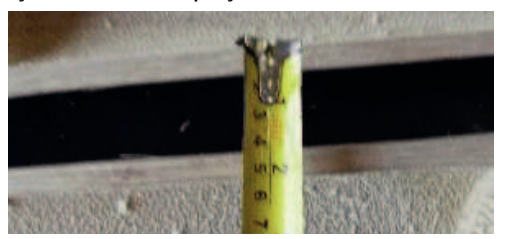

Fonte: Autores
Figura 4-Laje meia-cana.

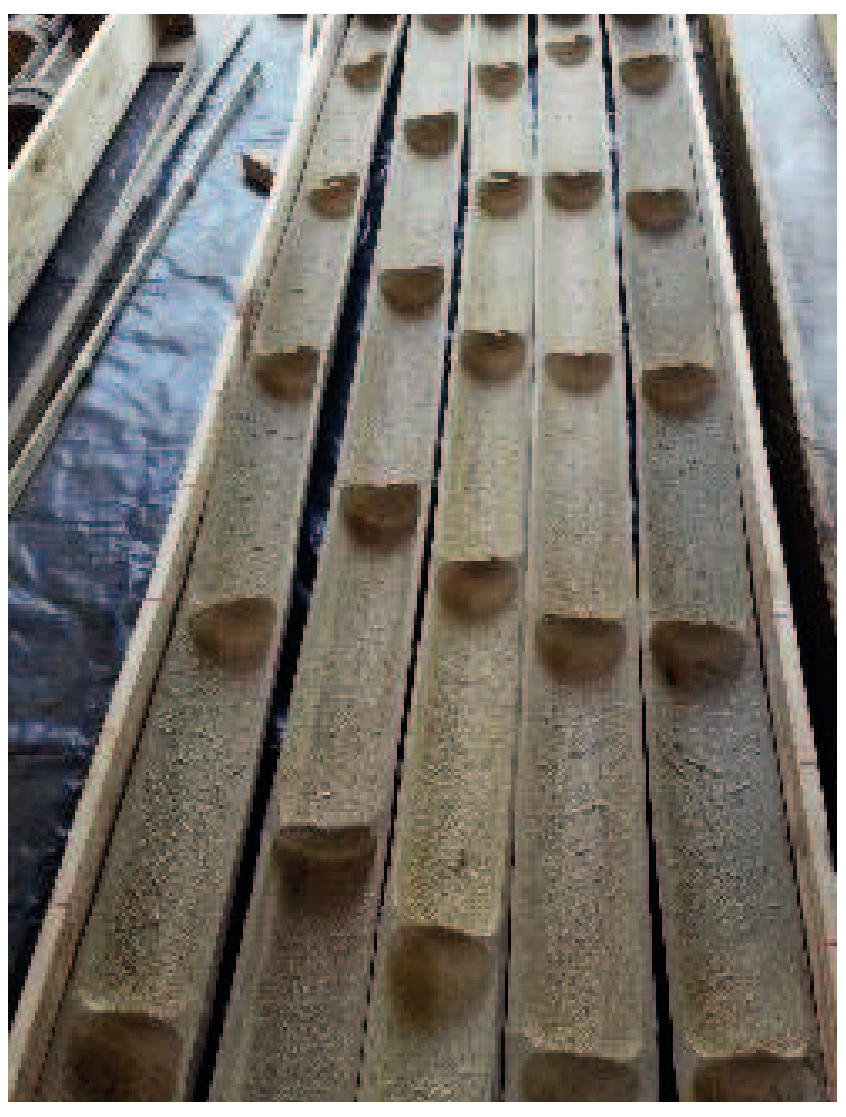

Fonte: Autores

Figura 5 - Malha de taliscas.

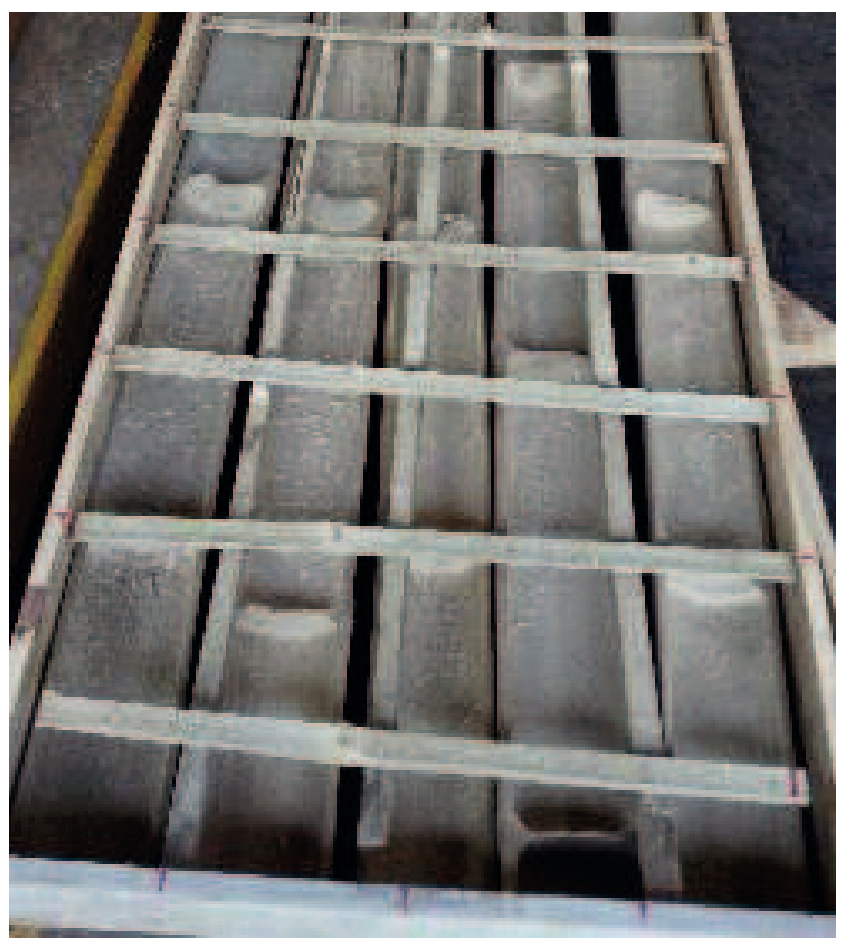

Fonte: Autores 
Figura 7 - Bambus com nós inteiros.

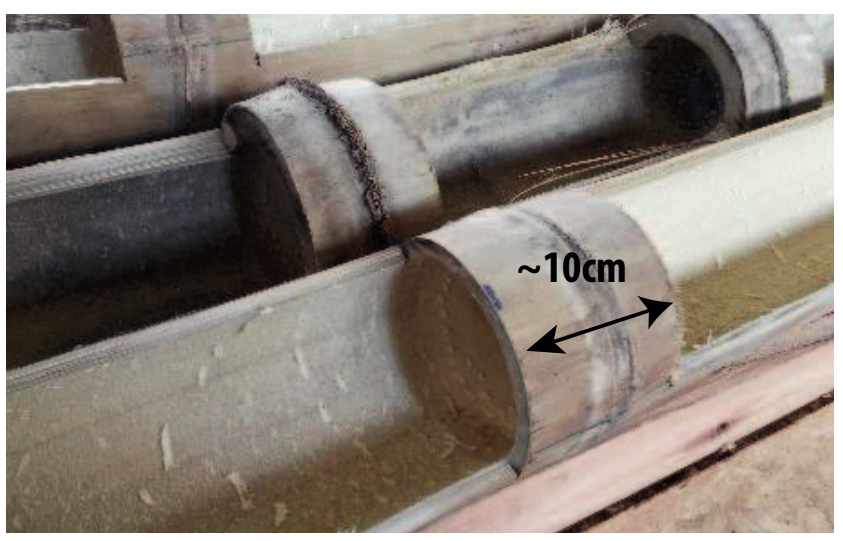

Fonte: Autores

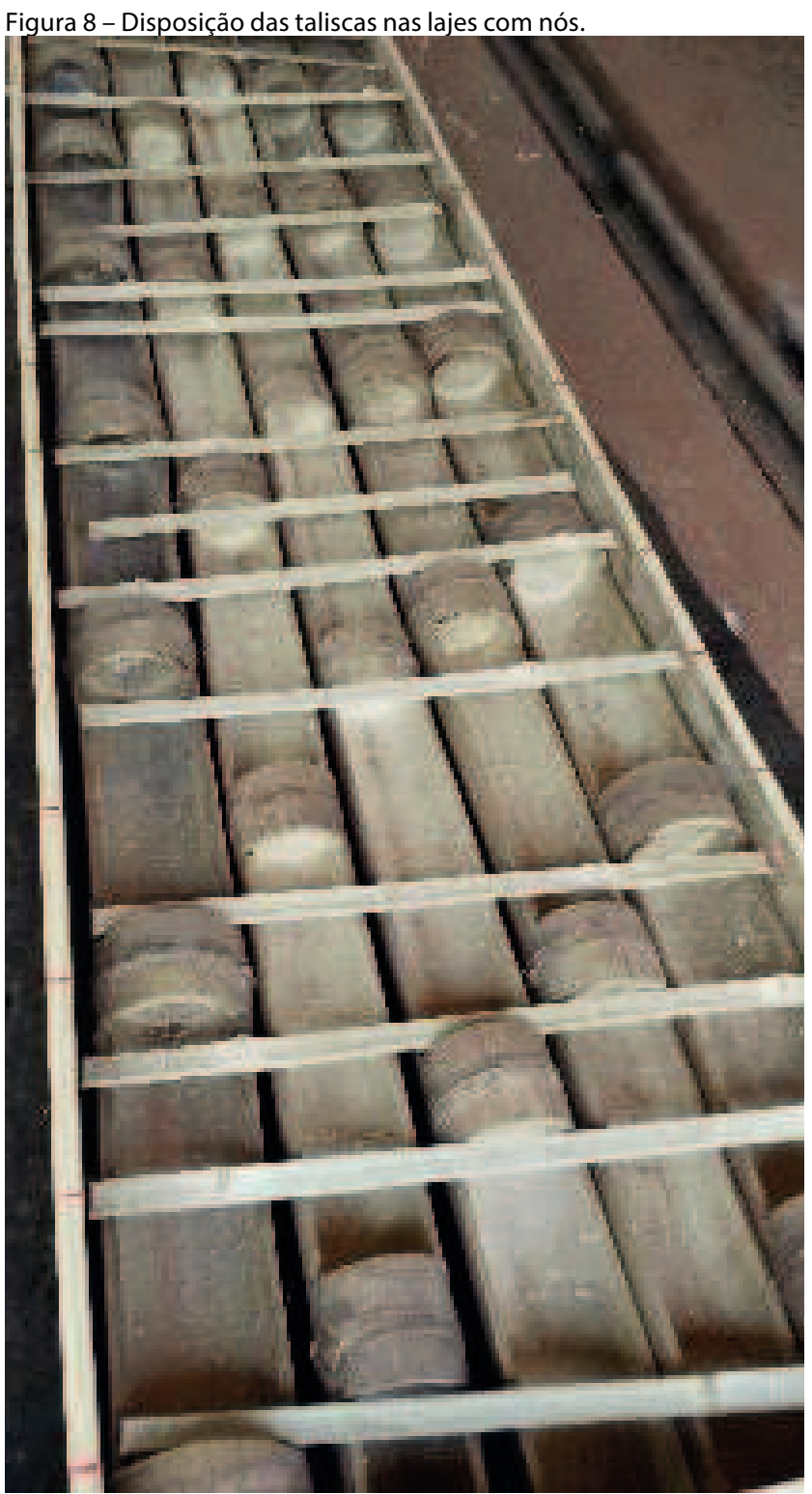

Fonte: Autores

\subsection{Concretagem}

Para o concreto foi utilizado agregado leve de argila expandida, seguindo o traço encontrado no site da empresa Cinexpan, indicado para concreto de fck, 28 de 15 $\mathrm{MPa}$, que consiste em 1:2,38:0,68 e relação água-cimento de 0,63. O traço escolhido foi ensaiado e verificado.

A concreto foi produzido em betoneira com capacidade de 400 Its do laboratório de materiais de construção da Universidade Estadual de Londrina.

Durante a produção e colocação do concreto, houve uma dificuldade em se obter uma mistura homogênea, pois a argila expandida ficou suspensa. Por outro lado, também observou-se uma separação entre o agregado graúdo e a pasta. Após a concretagem observou-se a suspensão do agregado leve (Figura 9).

Durante a concretagem foi observado que a estanqueidade da laje estava satisfatória, não havendo perda de pasta de cimento entre as varas de bambu.

Após a cura do concreto, foi realizada uma regularização da capa com utilização de argamassa de cimento e areia (Figura 10).

Figura 9 - Laje após concretagem.

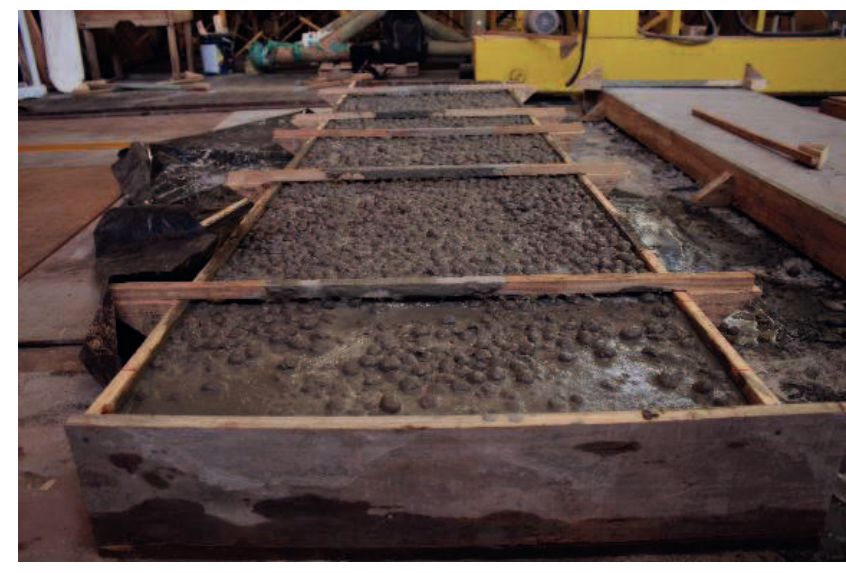

Fonte: Autores

Figura 10 - Laje após regularização da capa.

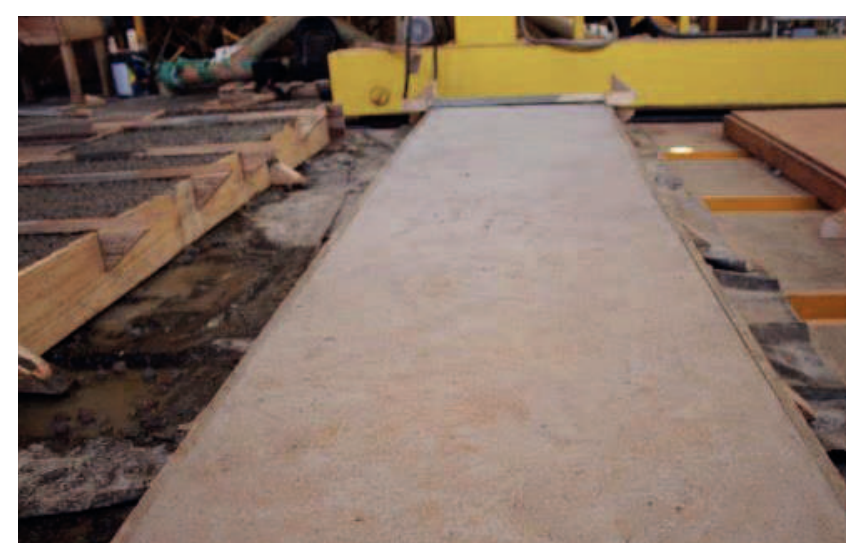

Fonte: Autores 


\subsection{Ensaio de Flexão}

O ensaio de flexão foi realizado no Laboratório de Estruturas da Universidade Estadual de Londrina. Para o ensaio, utilizou-se um pórtico de reação para de até 70 $\mathrm{KN}$, acoplado de um macaco hidráulico e uma célula de carga com capacidade de $100 \mathrm{KN}$.

O ensaio foi realizado aplicando-se uma carga pontual no centro do vão da laje, distribuída transversalmente por um perfil metálico. Três transdutores de deslocamento (LVDT) foram colocados no centro do vão, sendo um em cada extremidade da laje e um ao centro no macaco hidráulico, como mostrado na Figura 11. O posicionamento dos transdutores pode ser observado na Figura 12.

O ensaio de flexão foi realizado continuamente em velocidade constante até a ruptura da laje, sendo transferidos os dados de carga e deslocamento diretamente para o sistema de aquisição de dados.

Figura 11 - Posições dos LVDT's.

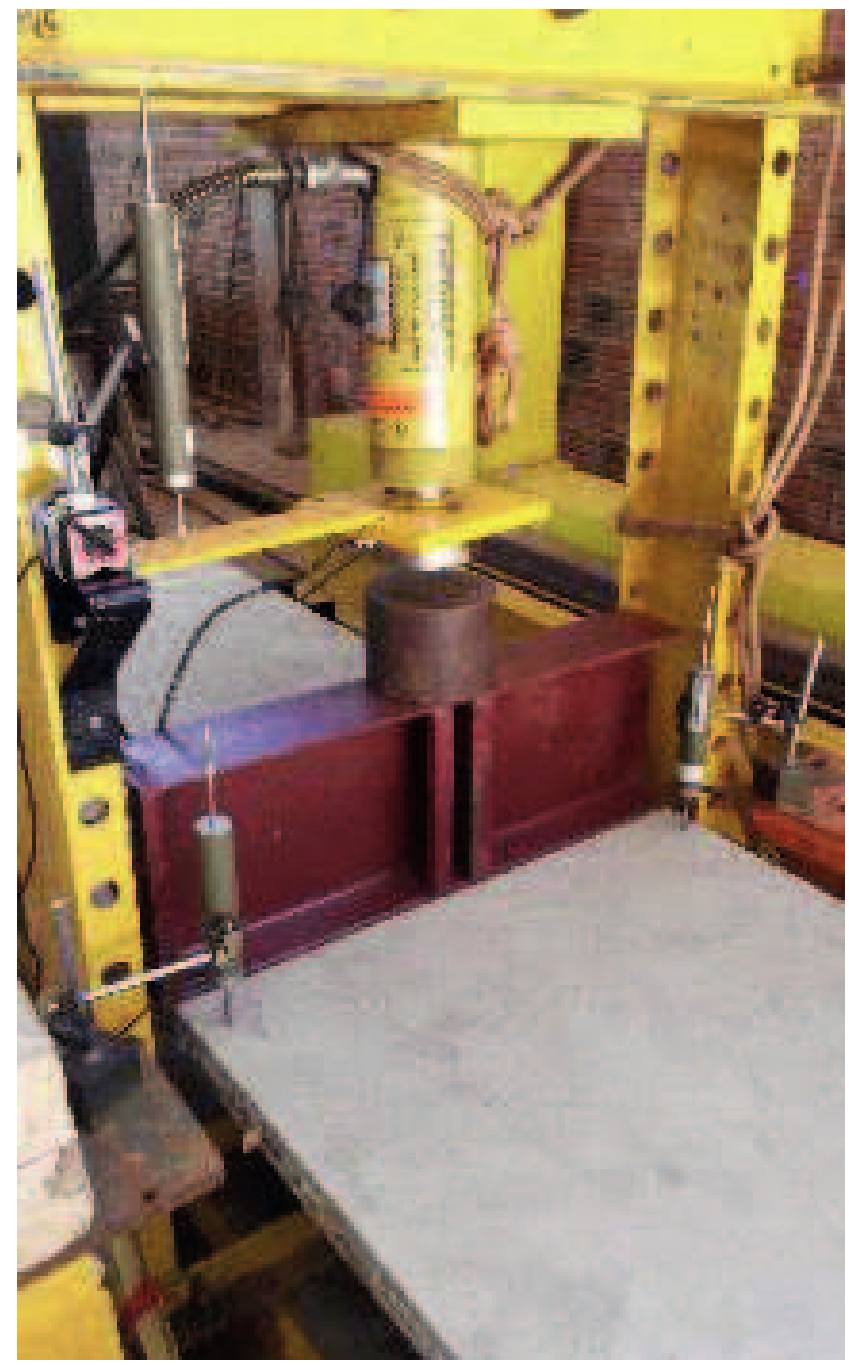

Fonte: Autores
Ao fim do ensaio foram retirados testemunhos para verificar a resistência do concreto utilizado na laje, com diâmetro de $50 \mathrm{~mm}$ e altura de aproximadamente $100 \mathrm{~mm}$.

Figura 12 - Posições dos LVDT,s 1 e 3.

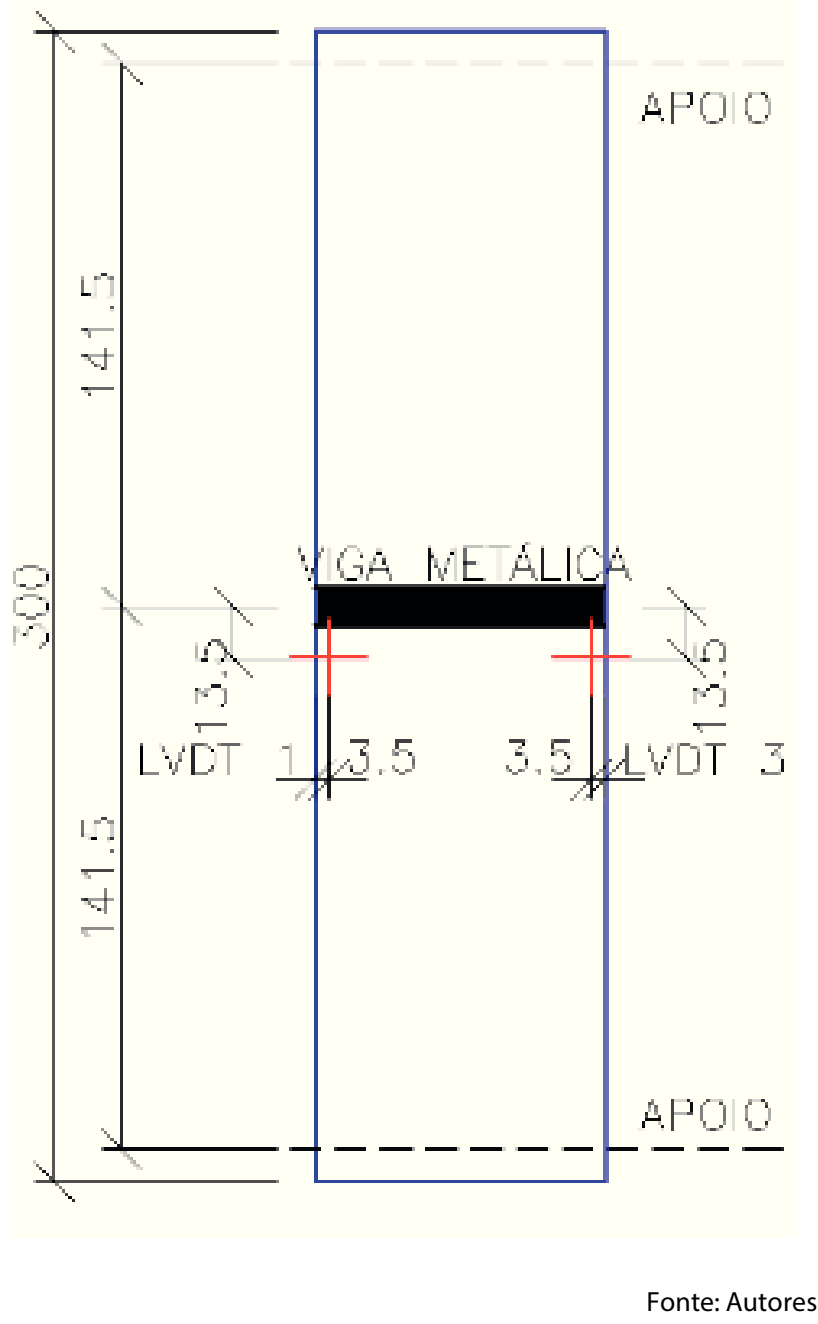

\section{RESULTADOS E DISCUSSÕES}

\subsection{Laje com varas de bambu a meia cana}

Conforme pode-se observar na Figura 13, a ruptura da laje ocorreu por compressão da capa de concreto, com um descolamento da parede do bambu do concreto entre os nós, em vários pontos (Figura 15 e Figura 16). O bambu não apresentou ruptura à tração, o que permitiu um comportamento dúctil da laje como um todo. Foi observado também escorregamentos do concreto em relação ao bambu na região dos apoios (Figura 14).

No gráfico da Figura 17, com a relação Carga $\times$ Deslocamento ( $\delta$ ), pode ser observado o comportamento inicial até $22 \mathrm{KN}$ foi linear, dando início à fase plástica da laje, suportando uma carga máxima de $30 \mathrm{KN}$. Ao final do ensaio 
a laje teve uma deformação superior ao curso do LVDT $(100 \mathrm{~mm})$, porém até o fim do carregamento o comportamento foi dúctil, não apresentando uma ruptura brusca.

Figura 13 - Ruptura da capa de concreto.

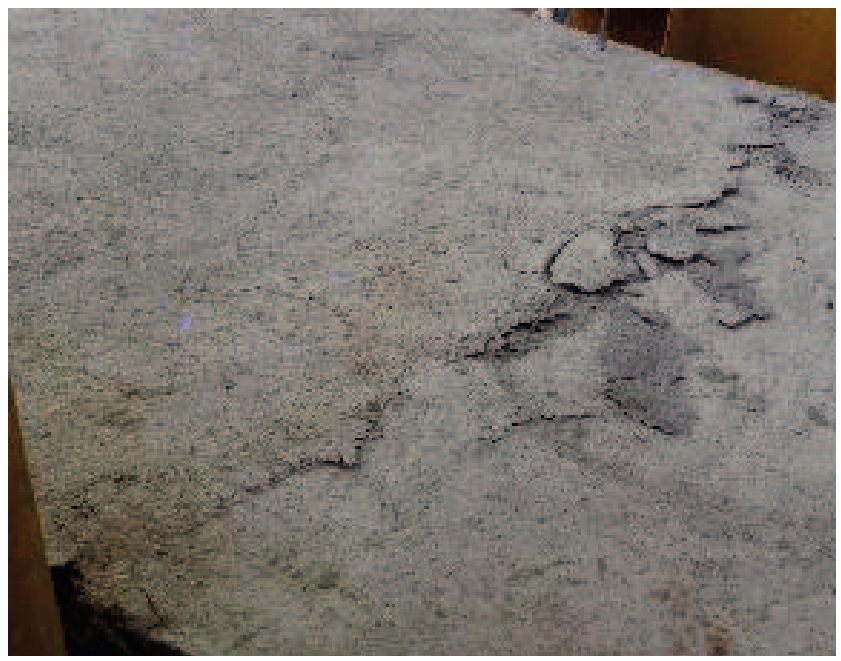

Fonte: Autores

Figura 14 - Deslizamento da massa de concreto no apoio.

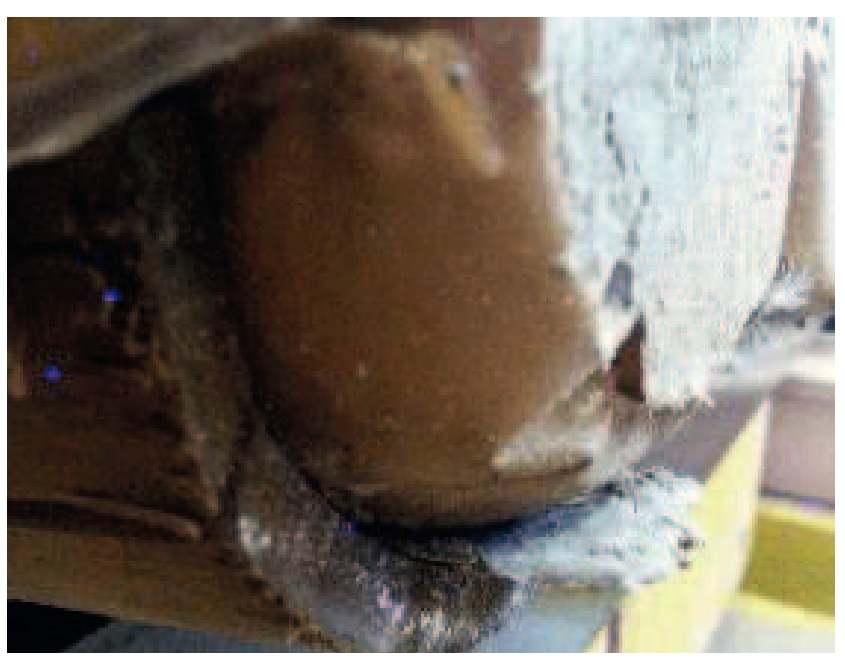

Fonte: Autores

Figura 15 - Deslocamento da aba do bambu externo.

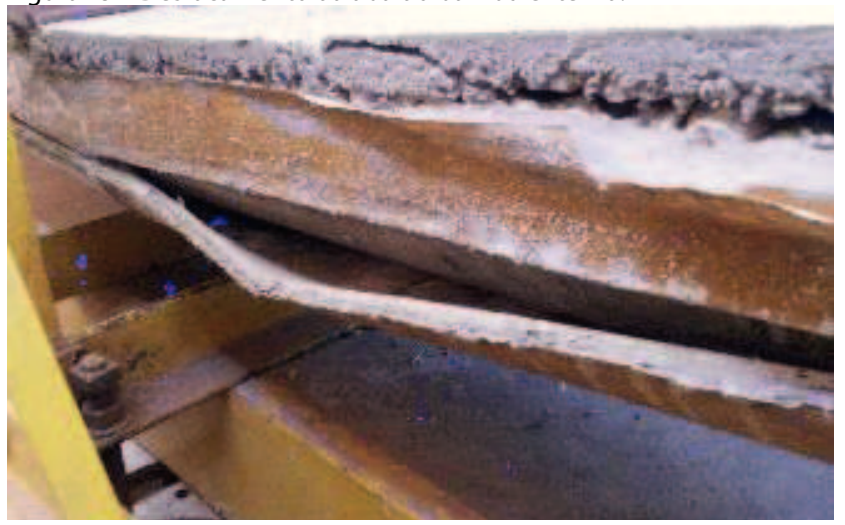

Fonte: Autores
Figura 16 - Deslocamento local do bambu no centro da laje.

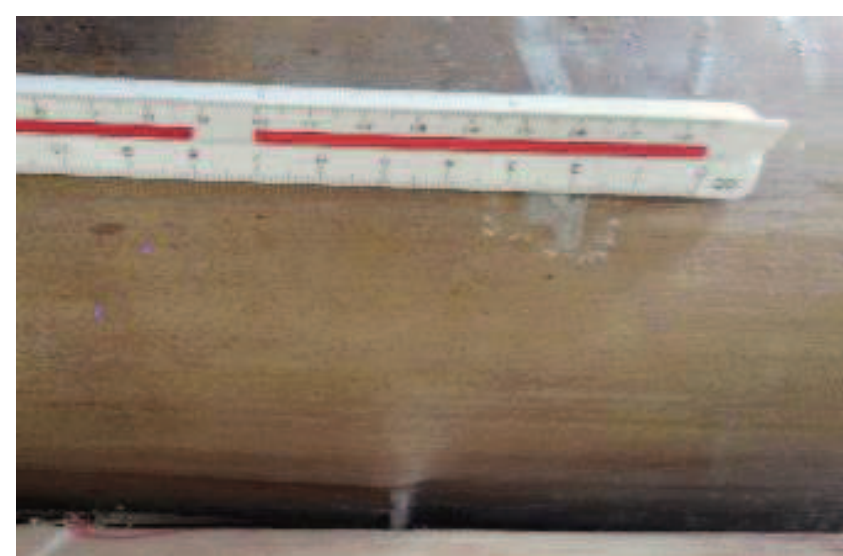

Fonte: Autores

Figura 17 - Diagrama Carga $\times$ Deslocamento, laje com varas a meia cana.

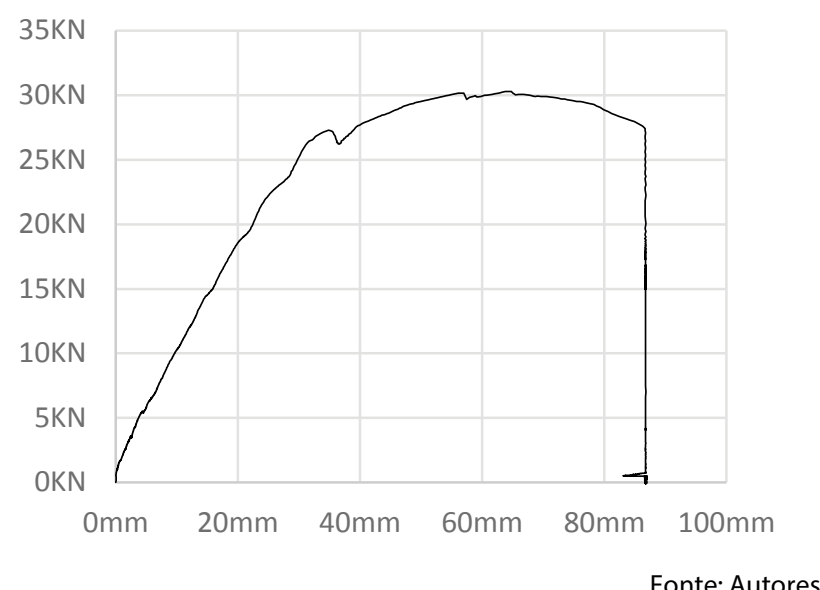

3.2. Laje com varas de bambu a meia cana entre nós e seção plena nos nós

No ensaio dessa laje foi observado um ganho na rigidez do conjunto em relação a laje cujas varas de bambu são completamente a meia cada.

A ruptura final ocorreu também na capa de concreto, porém por cisalhamento e compressão Figura 18. Da mesma forma que a laje anterior, houve deslizamento da massa de concreto em relação ao bambu na região dos apoios Figura 21, porém com menor intensidade. Foi observado também o cisalhamento dos nós do bambu, indicando que o mesmo estava trabalhando como conector entre o bambu e a capa de concreto (Figura 19 e Figura 20).

No gráfico da Figura 22 pode-se observar um comportamento mecânico quase linear da laje até a carga de, a partir do qual se inicia a falha dos mecanismos resistentes da laje. A ruptura foi de forma também de forma dúctil, porém um pouco menos que a laje cujas varas de bambu são em sua totalidade em meia cana. 
Apresentou grandes deslocamentos após que a carga máxima fosse atingida.

Como no caso da outra laje, o limite final do gráfico da Figura 22 foi limitado pelos medidoresde deslocamentos no total.

Figura 18 - Ruptura da capa de concreto.

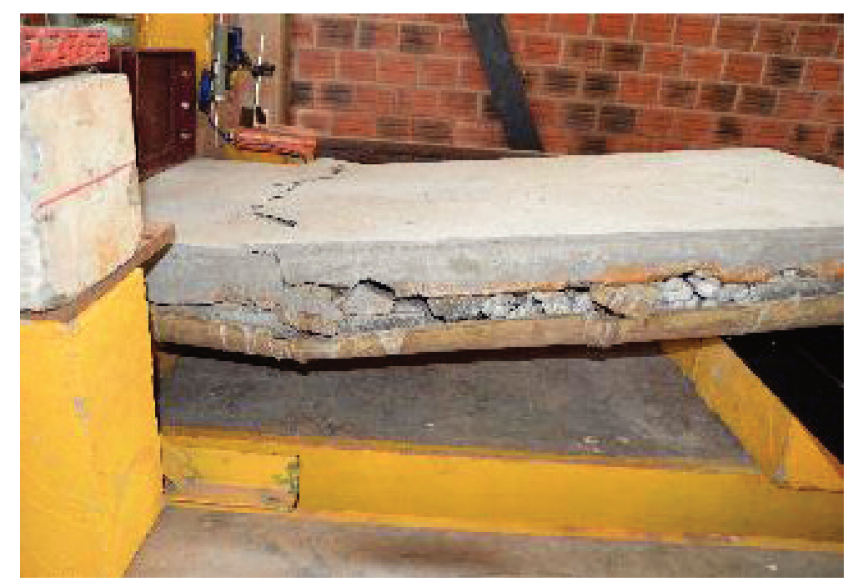

Fonte: Autores

Figura 19 - Ruptura do nó de bambu.

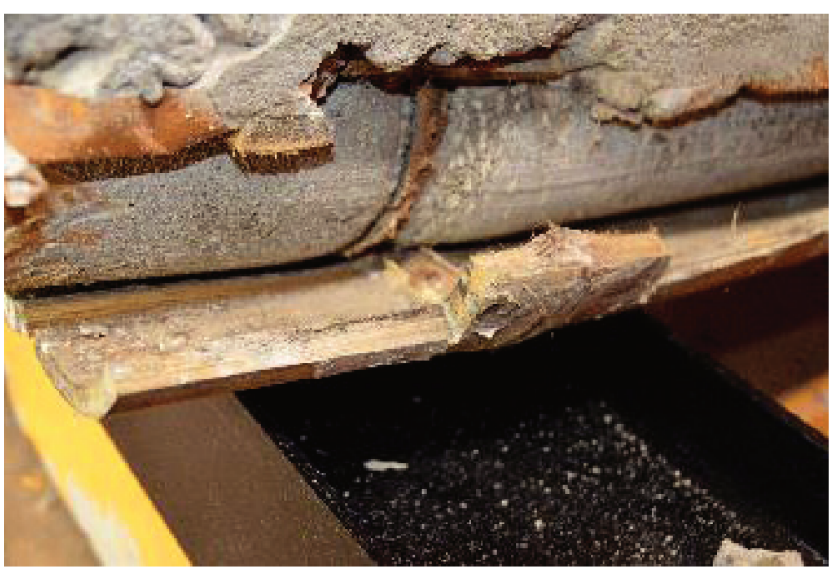

Fonte: Autores

Figura 20 - Ruptura do nó de bambu.

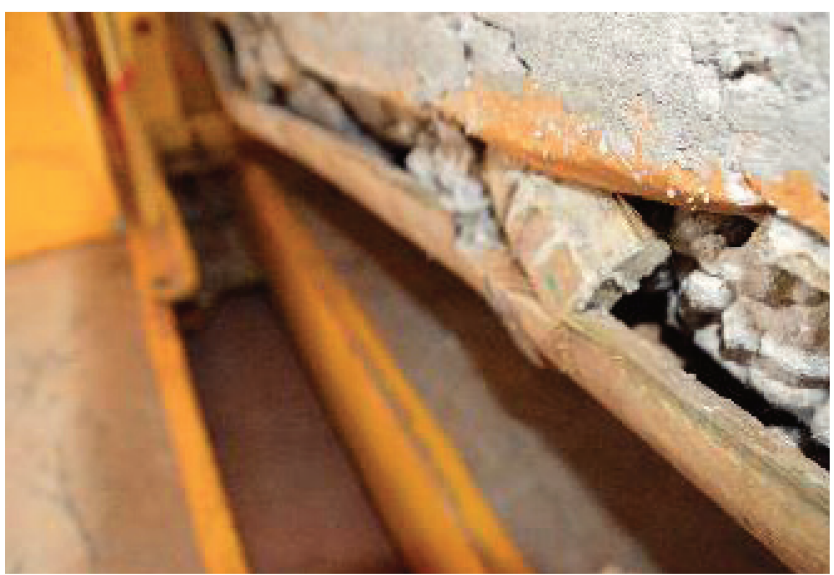

Fonte: Autores
Figura 21 - Deslizamento do concreto nos apoios.

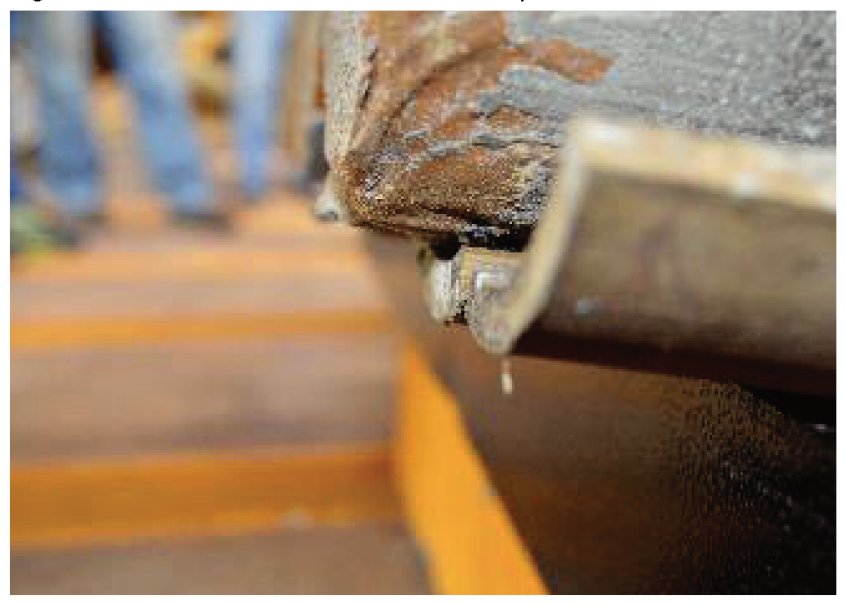

Fonte: Autores

Figura 22 - Diagrama Carga $\times$ Deslocamento, laje com varas a meia cana entre nós e seção plena nos nós.

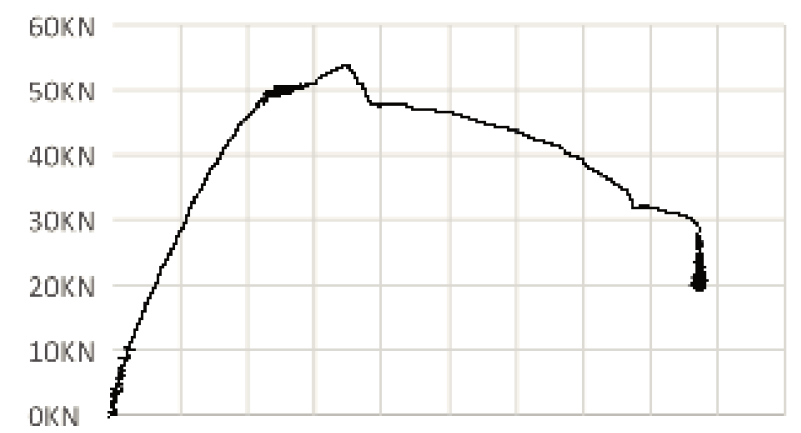

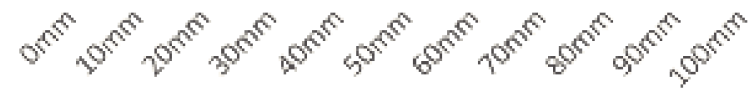

Fonte: Autores

\subsection{Análise teórica das lajes com relação a inter-} face entre o bambu e o concreto

Com o objetivo de contrastar os resultados experimentais obtidos nos ensaios das lajes com uma análise teórica, foi elaborada uma planilha de cálculo para determinar os deslocamentos teóricos da laje segundo duas hipóteses. Na primeira, considerou-se que os materiais estão perfeitamente conectados, ou seja, com perfeita transferência de esforços na ligação concreto-bambu, e na segunda, desconsiderou-se totalmente a interface de ligação, com os dois materiais resistindo às tensões internas separadamente. Em ambos os casos foi considerado que as varas de bambu são a meia cana.

Foram consideradas as dimensões medidas nas lajes executadas e ensaiadas. Para as propriedades mecânicas do bambu foi utilizado o valor de módulo de elasticidade obtido por CARBONARI et al (2015) de 21,85GPa. Para o concreto, os testemunhos retirados das lajes foram ensaiados à compressão, além da densidade. O módulo de elasticidade do concreto foi estimado de acordo com o EUROCODE 2 
(2004) para concretos leves, que corresponde a 16GPa, com o fck de 14,7 MPa e densidade ( $\rho$ ) de $1770 \mathrm{~kg} / \mathrm{m}^{3}$.

Considerando as propriedades físicas, mecânicas e geométricas na planilha de cálculo, foram obtidos os comportamentos mecânicos da laje, cujos diagramas estão apresentados no gráfico da Figura 23.

Figura 23 - Curva teórica Carga $\times$ Deslocamento.

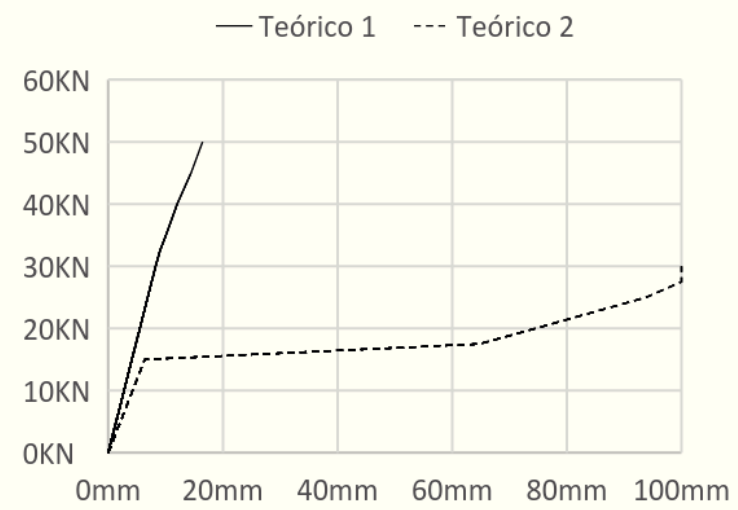

Fonte: Autores

Como pode ser observado no gráfico da Figura 23, o diagrama onde os materiais da seção são considerados perfeitamente conectados entre si (Teórico 1), apresentam um comportamento quase linear até a carga última, com uma pequena mudança na angulação pouco acima da carga de $30 \mathrm{KN}$, onde o concreto começa a fissurar. No outro diagrama, onde os materiais foram considerados não conectados entre si (Teórico 2), há um primeiro trecho linear até uma carga de $\sim 15 \mathrm{KN}$, a partir do qual há uma mudança brusca da inércia, da não fissurada para a inércia fissurada, caracterizada pela perda de resistência da capa de concreto.

\subsection{Comparativo dos resultados obtidos das la- jes ensaiadas}

Para que fosse possível efetuar uma comparação dos diagramas carga $\times$ deslocamento entre as duas lajes, foi necessário uniformizar as respectivas rigidezes, pelo fato que, após a concretagem, as capas de concreto ficaram diferentes, uma com 4,4 cm, e a outra com 5,8 cm. Após essa consideração, na Figura 24 constam os diagramas carga $\times$ deslocamento obtidos teoricamente e experimentalmente das lajes.

Comparando os diagramas experimentais das lajes na Figura 24, fica evidente o melhor comportamento mecânico que apresentou a laje cujas varas de bambu possuem seção plena na região dos nós, em relação a outra laje onde as varas são todas a meia cana.

Observa-se na referida figura que em ambos os diagramas as curvas obtidas nos ensaios das lajes ficam entre os gráficos teóricos, o que indica que em ambas as lajes os diafragmas do bambu atuam como conectores entre o a parte inferior do bambu e o concreto, seno mais evidente esta influência na laje com seção plena na região dos nós.

Figura 24 - Comparativo.
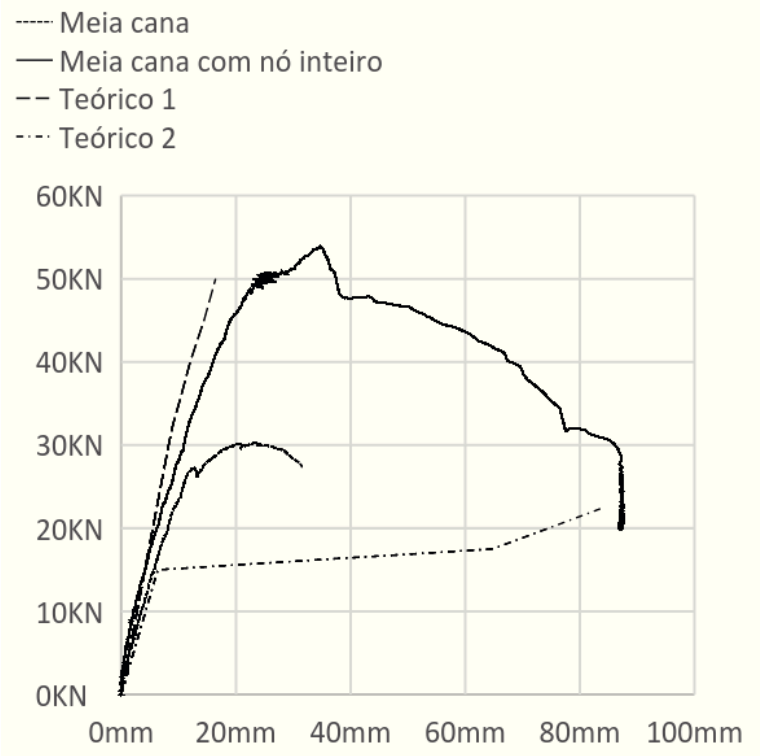

Fonte: Autores

\section{CONCLUSÕES}

Durante a fase de concretagem foi observado que o agregado leve ficou em suspensão na laje, o que é indesejável, pois é na capa superior que atuam as máximas de tensões de compressão na flexão.

Observou-se que mantendo a seção plena das varas de bambu na região dos nós, aumenta-se significantemente a resistência da laje mista bambu-concreto, em relação a laje onde todas as varas são em meia cana.

Mesmo com as deficiências na interface bambu-concreto, as lajes apresentaram um comportamento mecânico quase linear entre carga e deslocamento, em seu trecho inicial, e dúctil, de muito interesse para possíveis aplicações práticas.

Apesar de não ser representativo estatisticamente o número de lajes ensaiadas, ode concluir que esse tipo de laje pode ter um grande potencial de utilização em residências para vãos comuns, apresentando um baixo peso próprio e um bom comportamento mecânico.

\section{AGRADECIMENTOS}

A UEL, ao CNPq, e à Fundação Araucária, pelo apoio com bolsas de Iniciação Científica.

Aos laboratoristas Carlos e Luis Gustavo. 


\section{REFERÊNCIAS}

CARBONARI, G., SILVA JUNIOR, N. M., PEDROSA, N. H., ABE, C. H., SCHOLTZ, M. F., ACOSTA, C. C. V., CARBONARI, L. T. (2015). Propriedades mecânicas de várias espécies de bambu. In: XV ENCONTRO BRASILEIRO EM MADEIRAS E EM ESTRUTURAS DE MADEIRA. Anais... Curitiba. 2015.

EUROPEAN COMMITTEE FOR STANDARDIZATION (2004). Eurocode 2: Design of concrete structures. Part. 1-1: General rules and rules for buildings. Brussels. 2004.

FARRELY, D. The Book of Bamboo. Sierra Club Books, São Francisco, 1984, 202p.

GHAVAMI, K.; HOMBEECK, R. V. Apllication of bamboo as a construction material. Part I-Mechanical properties and water repellent treatment of bamboo Part II- Bamboo reinforced concrete beams. In: Latin American Symposium, Rational Organization of Building applied to Low-cost Housing, 1982, Sao Paulo. Rational Organization of Building Applied to Low-cost Housing. Sao Paulo : IPT, v. 1. p. 49-65, 1981.

GHAVAMI, K. (2005) Bamboo as reinforcement in structural concrete elements. Cement \& Concrete Composites 27. p. 637-649, 2005. 